\title{
NURSING PRACTICE
}

\section{The historical role and education of nurses for the care and management of sexually transmitted infections in the United Kingdom: 2 Education and training}

\section{K Miles}

The beginning of the 20th century saw the first attempts to educate nurses about sexually transmitted infections (STIs) in the United Kingdom. Throughout the century, numerous individuals and organisations campaigned for improved STI awareness education for nurses. Education initiatives gradually moved from the more generic nurse training programmes to the specialist courses for genitourinary medicine (GUM) nurses. Even so, it wasn't until the 1970s that these specialist courses were successfully implemented and sustained. Following a detailed review of nursing education and STIs over the past century, this paper speculates why programmes of STI education have never been sustained for the general nursing workforce. It then considers possible developments for future education agendas that will ultimately enable nurses to contribute more readily to the challenges that national sexual health and nursing strategies currently propose.

Series editor: Vanessa Griffiths

Correspondence to: Kevin Miles, nurse consultant, Mortimer Market Centre, off Capper Street, London WC1E 6AU, UK kmiles@gum.ucl.ac.uk

Accepted for publication 17 May 2002
$\mathrm{T}$ is is the second of two papers discussing the historical role and education of nurses in the specialty of sexually transmitted infections. The previous paper highlighted milestones in the role development of the genitourinary medicine (GUM) nurse. This paper provides a historical overview of how nursing education has dealt with the topic of sexually transmitted infections (STIs) over the past 100 years. The review commences during the first world war when nurses, and their subsequent education, were recognised for combating the upsurge of venereal diseases (VD). Following through to the end of the 20th century, the review traces the numerous attempts to provide education for nurses in general, and more specifically, nurses working in the specialty of GUM.

The review was conducted using journal and textbook publications and source documents from the Wellcome Institute for the History of Medicine Contemporary Medical Archives Centre and the Public Record Office in Kew, London. The findings are presented in chronological order of events and/or publication.

THE BEGINNING OF NURSE EDUCATION FOR VD CONTROL: FIRST WORLD WAR

One of the earliest attempts to educate nurses on the venereal diseases (VD) was by the Central
Midwives Board in 1916 who issued a series of leaflets giving nurses factual information about gonorrhoea and syphilis. ${ }^{1}$ Later in the same year, the National Council for Combating Venereal Diseases (NCCVD) received a letter from the National Union of Trained Nurses with regard to teaching nurses about VD. The medical committee of the NCCVD considered it "desirable that nurses should receive special instruction on venereal diseases, especially as regards the dangers of infection." It was decided that this resolution should be conveyed to the National Union of Trained Nurses, and that they should be asked to convey this to the matrons with whom they were in touch. ${ }^{2}$ However, VD being a new concept for nurse education, there appeared to be little direction in providing this instruction to nurses.

In January 1917, the NCCVD committee received a letter from Miss Hay Cooper asking whether it would be possible for VAD nurses to be given some instruction as to the dangers of venereal diseases (to nurses) in the infectious stage. It was agreed that a copy of this letter should be sent to the headquarters of the British Red Cross Society, and that this society should be asked whether it would be possible to make arrangements for such instruction.

A year later at the January 1918 meeting, the committee found "it desirable to obtain the personal co-operation of nurses in the campaign [against VD], and that adequate instruction should be given to the nurses by the members of the medical staff in regard to the precautions which should be taken by nurses." ${ }^{4}$ At the next meeting in February 1918, hospitals requested a sample syllabus for medical staff to teach nurses. It was felt that "the most important thing to emphasise was the prevention of accidental infection by the nurses possessing suitable knowledge as to the dangers involved in nursing such cases." In March 1918, "the syllabus was practically complete ... a single lecture giving the main points of the dangers of infection and one longer syllabus which would serve for two lectures dealing with the medical aspect and also the wider social aspect of the problem.." ${ }^{\prime 6}$ The matter wasn't addressed in the minutes again until April 1919 when the medical committee considered advocating a special course of training and certification in VD for nurses.

\section{A COURSE OF VD INFORMATION FOR NURSES: 1920}

In January 1920, there was evidence of hospitals already providing VD instruction to nurses, and 
those arranging to give instruction. ${ }^{8}$ Later that year, the medical committee was still discussing a course for nurses and discussed whether the Institute of Hygiene could provide this. ${ }^{9}$ The institute was responsive and ready to help in any way. They suggested four lectures: ( 1 ) dealing with the sociological aspect of VD, (2) a lecture on syphilis, (3) a lecture on gonorrhoea, (4) a lecture particularly directed towards the incidence and prevention of both diseases with special reference to children. $^{10}$

From here on, the momentum for training nurses diminished until it was raised again in February 1923:

Dr Fairfield asked whether the council could take any action in regard to the training of nurses in venereal diseases as it was apparent that a number of the hospitals were not using the VD clinics as training ground for their staff. It was agreed that a circular letter should be sent to the hospitals drawing their attention to the necessity for training their nurses. ${ }^{11}$

\section{NURSES AS BARRIERS TO PROGRESSION: 1920s}

It was not only the degrees of bureaucracy that delayed the instruction of nurses in the venereal diseases, but also the nurses themselves. Clarkson and Cantab (1922) wrote of the existing stigma within the nursing profession:

It should be realised that the stigmatic position which is so frequently adopted towards patients suffering from venereal disease is one which is as entirely inconsistent with the tradition of the nursing profession as it is uncharitable and ignorant. ${ }^{12}$ (p 360)

In April 1923, the NCCVD investigated the training of nurses in VD treatment centres. Of 191 letters sent by the NCCVD to treatment centres across England and Wales, only 20 replies were received. Seven of these were merely acknowledgements. ${ }^{13}$ At the same time a letter had also been sent to the Ministry of Health $(\mathrm{MoH})$ asking if the training of nurses could be made a definite part of the $\mathrm{MoH}$ venereal disease scheme. The Ministry of Health felt that they were unable to do anything and suggested writing to the General Nursing Council (GNC). The next meeting of the NCCVD Medical Committee reported approaches to the College of Nursing, the Royal British Nursing Association, and the Queen Victoria Jubilee Nursing Institute in an attempt to get venereal diseases on the nursing curriculum. ${ }^{14}$ The GNC responded by saying they were to include the physiology of the reproductive system in the nursing training syllabus. ${ }^{15}$ The medical committee felt this was insufficient for dealing with the issues surrounding venereal diseases and decided to readdress the matter in 2 months. ${ }^{16}$ Of the existing minutes of the NCCVD Medical Committee that continued until 25 March 1926, there was no further mention of nurse training.

\section{STILL NO SUSTAINED CURRICULUM IN SIGHT: 1932-50}

Nearly 10 years later, correspondence regarding the training of nurses on venereal diseases recommenced, this time between the Central Midwives Board (CMB) for Scotland and the British Social Hygiene Council. In May 1932, the CMB (Scotland) considered giving practical teaching to pupil midwives on the subject of venereal diseases in pregnant women. ${ }^{17}$ They followed this up in November 1932 with a letter to the British Social Hygiene Council requesting more adequate VD training for midwives. ${ }^{18}$

Around the same time, the CMB (for England and Wales) also wrote to the British Social Hygiene Council regarding difficulties in obtaining proper teaching for pupil midwives in England and Wales. ${ }^{19}$ In March 1933, the British Social Hygiene Council discussed the practical training in VD for midwives. ${ }^{20}$ This was pursued in 1933 with a letter to a Dr
Fairburn to assist with "a regional plan of approved places of instruction of VD for midwives.".21

Twelve years later the British Social Hygiene Council wrote to the $\mathrm{CMB}$ :

Considering various problems in the training of nurses and health visitors ... without in any way criticising their training in this respect, I should be grateful if your Board would consider whether it is sufficient to make them competent to advise on these problems. ${ }^{22}$

The CMB responded to the chairman of the British Social Hygiene Council advocating the importance of a midwife "having a sound knowledge of VD and its social implications."23

Five years later, the matter of VD training for midwives had made little progress. A letter from the secretary of the CMB stated: "Instruction on venereal diseases should be given in both periods of training ... in the second period of training the emphasis is much more practical ...." ${ }^{24}$ Demonstrations and visits to VD clinics were also advocated.

In 1956, Aids to the Nursing of Venereal Diseases ${ }^{25}$ was published by a state registered nurse (SRN) with a VD certificate from the Royal College of Nursing (RCN). The author wrote that the RCN offered courses for SRNs working or willing to work in a VD clinic for 3 months. However, Ryle-Horwood quoted that "sufficient nurses will not be recruited unless a special effort can be made to interest student nurses in the subject" (p 2).

\section{A COURSE SUSTAINED AT LAST: 1970s}

Despite the periodic attempts to educate nurses on venereal diseases over a 70 year period, there appeared to be no programmes that were sustained in the teaching of venereal diseases until the 1970s. In 1971, the Joint Board of Clinical Nursing Studies (now the English National Board (ENB) for Nursing, Midwifery and Health Visiting) organised a venereal diseases panel to discuss a course in VD for nurses. ${ }^{26}$

A 24 week course (later known as ENB 275) was initiated in 1972 for registered and enrolled nurses to fulfil a specified role in "special clinics" for venereal and other sexually transmitted diseases.$^{27}$ This course included classroom teaching with clinical experience in a "special clinic" and laboratory, and visits into the community for contact tracing. The teaching consisted of task skill development, preparing for and assisting during procedures, and administration procedures. The specific nursing skills taught included taking specimens, staining, microscopy and culture techniques, venepuncture, examination and interpretation of urine specimens, making and interpreting clinical observations, and taking appropriate action. The nurse was taught to prepare and assist for genital/ rectal examination, proctoscopy, urethroscopy, cytology, and lumbar puncture. Administration procedures included contact tracing, taking charge of the clinic, and general administration procedures. By 1979, there were four centres conducting the course with 40 places available per year and 131 certificates had been issued. ${ }^{28}$

In 1980, a further short course in sexually transmitted disease (STD) nursing was planned. ${ }^{29}$ The course, later to be known as the ENB 932, was launched in 1982 and targeted nurses with a minimum of 3 years' experience in the specialty. ${ }^{30}$

\section{RESEARCHING THE TRAINING REQUIREMENTS OF GUM NURSES: 1987}

In the mid-1980s, a study exploring the role and training of nurses in GUM found that training was generally on the job in addition to the ENB 6 month course (ENB 275) for state registered nurses (SRNs) and state enrolled nurses (SENs). ${ }^{31}$ In addition to this long course, the ENB continued to run a short 5 day update course (ENB 932). The study concluded that all student nurses required more teaching about STDs and that 
specific training and updating of nurses working in GUM clinics be instituted. These recommendations were made as the General Nursing Council had, at this point, laid down no specific guidelines concerning the time or content of nurse teaching in sexually transmitted diseases.

\section{THE CURRICULUM STATUS IN 2002}

Nurses receive some training in sexuality and sexual health at pre-registration level ${ }^{32}$ but there are no specific requirements to incorporate fundamental elements of sexually transmitted infections. With regard to GUM nurses, the Genitourinary Urinary Nurses Association (GUNA) surveyed 90 universities in the United Kingdom in 1999. They identified 45 universities offering over 120 courses relevant to GUM nurses. The majority of these courses were ENB certificate courses in GUM, family planning, and HIV/AIDS. However, although accredited to do so, many of these university courses are not running owing to too few applicants.

\section{DISCUSSION}

This historical review has shown how efforts to initiate the education and training of nurses on the subject of sexually transmitted infections have fluctuated over the past 85 years. This has occurred despite the campaigning efforts of individuals, professional nursing bodies, venereologists, and other national organisations such as the National Council for Combating Venereal Diseases. There appear to have been a number reasons why no campaign was successful in securing a sustained programme of STI education until the 1970s. Firstly, bureaucracy, poor momentum, and lack of continuity appeared to be key to the delay in initiating education programmes. In the surviving NCCVD correspondence, there were often lengthy gaps between raising the issue of nurse education, making decisions, and taking action. Although it was difficult to pinpoint reasons for these delays from the archived evidence, it is likely this could have resulted from other priorities that organisations, such as the NCCVD, were committed to addressing during recorded STI epidemics. Secondly, after decisions were made it appeared that the capability and capacity to follow through with appropriate action was simply not available. For example, in 1916 when the NCCVD suggested it was desirable for nurses to be educated about the venereal diseases, there was considerable delay in clarifying who should conduct the teaching and what the content of teaching should entail. Finally, nurses themselves proved to be a barrier to further education. The stigma within the nursing profession, as suggested by Clarkson and Cantab (1922), was one example, and the complacency of the General Nursing Council who suggested physiology of the reproductive system in the nursing training syllabus was adequate, yet another. Ryle-Horwood (1956) also quoted that nurses' interest in the subject needed to increase in order to improve recruitment into training programmes.

After nearly 70 years of attempting to introduce and sustain nursing education for the control and management of STIs, the English National Board (formerly the Joint Board for Clinical Nursing Studies) initiated a number of courses during the 1970s. These courses still exist today. However, there are still a number of contemporary issues to be considered. Firstly, teaching sexual health to pre-registration nursing students is still left to the discretion of individual teaching programmes, with many not including it. ${ }^{32}$ Following registration, GUM/STI courses are primarily targeted at nurses who work in the specialty of GUM and not those who work in mainstream nursing roles. As a result, nurses working in non-GUM environments will often have little exposure throughout their career to any education on the topic of sexually transmitted infections. This is of particular concern given that the National Strategy for Sexual Health and HIV proposes a broader role for those working in primary care settings. ${ }^{33}$ The final issue concerns the

\section{Key messages}

- Efforts to educate the general nursing workforce on STIs have not been sustained and specialist GUM courses have existed since the 1970s

- The core elements of sexual health need to be incorporated into general pre-registration and post-registration nursing courses

- Supportive infrastructures need to be in place for primary care nurses to effectively contribute to the national sexual health strategy

- Nurses working in advanced GUM practice roles require access to appropriate preparation and continuing professional development programmes that address the issues of advanced genitourinary nursing practice

development of advanced roles for GUM nurses. The National Strategy for Sexual Health and HIV proposes that GUM nurses will have an expanding role as specialists and consultants in providing specialist sexual health services. ${ }^{33}$ Many GUM nurses are, to some degree, already working in such capacities. However, there is little evidence to suggest that current education curriculums have changed to reflect these developments in GUM nursing practice.

Therefore, for nurses to effectively contribute to the control of STIs in the new millennium, a number of issues require consideration. Nurses need to have the core elements of sexual health and STIs consistently incorporated into preregistration and post-registration education programmes across the United Kingdom. Sexual health should no longer be treated as a separate entity only for those working in GUM. This issue has been comprehensively addressed in the Royal College of Nursing Sexual Health Strategy. ${ }^{34}$

Secondly, supportive infrastructures that include initial education, skills training, competency assessment, and ongoing development need to be developed for primary care nurses to provide a level of sexual care. The Medical Society for the Study of Venereal Diseases (MSSVD) STI Foundation (STIF) course is one option for teaching primary care nurses about the core components involved in STI management. The STIF course also sets a precedent for interprofessional training in this field. Among other things, interprofessional training can encourage professionals to learn from and about each other and encourage respect for the contribution each professional has to make to patient care. ${ }^{35}$

Finally, nurses working in specialist and advanced GUM practice roles require access to appropriate preparation and continuing professional development programmes that address the issues of advanced GUM nursing practice. As a start, two London GUM services have collaborated to provide a 2 day workshop to introduce participants to the concept of nurse led STI care. Another collaboration between the MSSVD, the London Standing Conference Sexual Health Working Group, and the Genitourinary Nurses Association is working towards developing a competency based practice improvement programme that will be nationally recognised for progressing the role of the GU nurse.

In summary, to achieve all of these goals, coordinated efforts between educators, practitioners, acute GUM and primary care services, and professional nursing and GUM organisations are now required. Failure to do so could result in history repeating itself once again.

\section{ACKNOWLEDGEMENTS}

I would like to thank Barbara Mortimer, UK Centre for the History of Nursing, and Lesley Hall, The Wellcome Institute Contemporary Medical Archives Centre, for their advice and direction; and Danielle Mercey and Robert Power for their valuable comments during the preparation of this paper.

Conflicts of interest: none. 


\section{REFERENCES}

1 STD information leaflets issued by the Central Midwives Board. (DV 11/214). Kew: Public Record Office, 16-3-1916.

2 NCCVD. Minutes of a meeting of the medical committee. (SA/BSH). London: The Wellcome Institute Contemporary Medical Archives Centre 30-10-1916.

3 NCCVD. Minutes of a meeting of the medical committee. (SA/BSH). London: The Wellcome Institute Contemporary Medical Archives Centre, 19-1-1917.

4 NCCVD. Minutes of a meeting of the medical committee. (SA/BSH) London: The Wellcome Institute Contemporary Medical Archives Centre 28-1-1918.

5 NCCVD. Minutes of a meeting of the medical committee. (SA/BSH). London: The Wellcome Institute Contemporary Medical Archives Centre, 25-2-1918.

6 NCCVD. Minutes of a meeting of the medical committee. (SA/BSH) London: The Wellcome Institute Contemporary Medical Archives Centre, 25-3-1918.

7 NCCVD. Minutes of a meeting of the medical committee. (SA/BSH) London: The Wellcome Institute Contemporary Medical Archives Centre 28-4-1919.

8 NCCVD. Minutes of a meeting of the medical committee. (SA/BSH). London: The Wellcome Institute Contemporary Medical Archives Centre, 5-1-1920.

9 NCCVD. Minutes of a meeting of the medical committee. (SA/BSH). London: The Wellcome Institute Contemporary Medical Archives Centre, 8-11-1920

10 NCCVD. Minutes of a meeting of the medical committee. (SA/BSH). London: The Wellcome Institute Contemporary Medical Archives Centre, 13-12-1920

11 NCCVD. Minutes of a meeting of the medical committee. (SA/BSH). London: The Wellcome Institute Contemporary Medical Archives Centre, 5-2-1923.

12 Clarkson ERT, Cantab MA. The venereal clinic. London: John Bale, Sons and Danielsson Ltd, 1922.

13 NCCVD. Minutes of a meeting of the medical committee. (SA/BSH). London: The Wellcome Institute Contemporary Medical Archives Centre, 23-4-1923

14 NCCVD. Minutes of a meeting of the medical committee. (SA/BSH). London: The Wellcome Institute Contemporary Medical Archives Centre 11-6-1923.

15 NCCVD. Minutes of a meeting of the medical committee. (SA/BSH). London: The Wellcome Institute Contemporary Medical Archives Centre, 25-1-1923.

16 NCCVD. Minutes of a meeting of the medical committee. (SA/BSH). London: The Wellcome Institute Contemporary Medical Archives Centre, 8-10-1923.
17 Central Midwives Board for Scotland minutes. (DV 11/214). Kew: Public Record Office, 13-5-1932.

18 Letter from Central Midwives Board for Scotland to British Social Hygiene Council. (DV 11/214). Kew: Public Record Office, 8-11-1932.

19 Letter from Central Midwives Board to British Social Hygiene Council. (DV 11/214). Kew: Public Record Office, 31-10-1932.

20 British Social Hygiene Council minutes. (DV 11/214). Kew: Public Record Office, 17-3-1933

21 Letter from British Social Hygiene Council to Dr Fairburn. (DV 11/214). Kew: Public Record Office, 5-10-1933.

22 Letter to Central Midwives Board from British Social Hygiene Council. (DV 11/214). Kew: Public Record Office, 27-2-1945.

23 Letter from Central Midwives Board to Chairman of the British Social Hygiene Council. (DV 1 1/214). Kew: Public Record Office 7-4-1945

24 Letter from Secretary of the Central Midwives Board. (DV 11/214). Kew: Public Record Office, 25-10-1950.

25 Ryle-Horwood EM. Aids to the nursing of venereal diseases. London: Bailliere, Tindall \& Cox, 1956.

26 Joint Board of Clinical Nursing Studies. Minutes of the Venereal Disease Panel. (DY 1/116). Kew: Public Record Office, 1-7-1971.

27 The Joint Board of Clinical Nursing Studies. Outline curriculum: Nursing of Venereal and other Sexually Transmitted Diseases for State Registered Nurses and State Enrolled Nurses. (DY 1/43). Kew: Public Record Office, 1972.

28 Joint Board of Clinical Nursing Studies. Minutes of the Venereal Disease Panel. (DY 1/1 16). Kew: Public Record Office, 26-9-1979.

29 Joint Board of Clinical Nursing Studies. Minutes of the Venereal Disease Panel. (DY 1/1 16). Kew: Public Record Office, 23-4-1980.

30 The Joint Board of Clinical Nursing Studies. Sexually Transmitted Diseases nursing - short course leaflet. (DY 1/173). Kew: Public Record Office, 1982

31 Rogers JS, Adler MW. Role and training of nurses working in departments of genitourinary medicine in England and Wales. 2. Training and future role. Genitourin Med 1987;63:127-32.

32 Mulholland $\mathbf{H}$. Is nurse's sex education growing and changing? Nurs Times 2001:97:13.

33 Department of Health. The national strategy for sexual health and HIV London: Department of Health, 2001

34 Royal College of Nursing. RCN sexual health strategy: Guidance for nursing staff. London: Royal College of Nursing, 2001.

35 Finch J. Interprofessional education and teamworking: a view from the education providers. BM 2000;321:1138-40. 